\title{
Anopheles nili as the main vector of human malaria in villages of southern Cameroon
}

\author{
P. CARneVAlE, G. LE GOFF, J.-C. TOTO and V. ROBERT \\ Medical Entomology Department, Antenne ORSTOM auprès de l'O.C.E.A.C., Yaounde, Cameroon
}

\begin{abstract}
In villages near Sanaga river, in the forest zone of south Cameroon, Anopheles nili Theobald is the main species of mosquito regularly found biting man inside houses. Its densities are related to the flow level of the river. It is also the main malaria vector in terms of intensity and seasonal duration of transmission. The yearly malaria inoculation rate due to An.nili alone is 104 infective bites/man, varying between 3 infective bites/man in October and 20 in March. Anopheles gambiae Giles is a less important vector in the area but reached its peak in the dry season, when the Sanaga river is at its lowest level. These observations underline the influence of local ecology on malaria transmission and the need for entomological studies in each situation.
\end{abstract}

Key words. Anopheles nili, Anopheles gambiae, malaria vectors, vector bionomics, malaria transmission, Cameroon.

\section{Introduction}

Since the work of Hamon \& Mouchet (1961), Anopheles nili Theobald has been regarded as merely a local or temporary vector of human malaria, relatively less important than An.gambiae Giles and An.funestus Giles which are considered to be the main vectors of malaria in Africa south of the Sahara (Gillies \& De Meillon, 1968; Gillies \& Coetzee, 1987). The local importance of An. nili has been documented in the forest zones of southern Cameroon (Hamon et al., 1956), Nigeria (Service, 1964), Ethiopia (Krafsur, 1970), Congo (Carnevale, 1974; Carnevale et al., 1978) and Burkina Faso (Gayral et al., 1975).

The current upsurge of drug-resistant strains of P.falciparum in Africa has renewed interest in malaria vector control. One of the methods currently envisaged is the large-scale use of insecticide treated bed nets (Curtis, 1989) which reduce the contact between man and vectors, thus reducing both inoculation rate and malaria morbidity. In preparing the framework for such a vector control programme involving $A n$.nili, we collected entomological base-line data in villages located near the Sanaga river, southern Cameroon, where malaria is holoendemic and Mouchet (1962) studied An.gambiae biology. The climate is characterized by two rainy seasons: March-

Correspondence: Dr P. Carnevale, Medical Entomology Department, Antenne ORSTOM auprès de I'O.C.E.A.C., B.P. 288, Yaounde, Cameroon.
June and August-November, and two dry seasons: July and December-February (Fig. 1).

For financial reasons, the local villagers have no special protection against the bites of mosquitoes.

\section{Materials and Methods}

Three villages were chosen in the forested area, near to the Sanaga river (Le Goff et al., 1990). This is a permanent river, but when its waters are low during December-June (Fig. 1) there are plentiful rock pool breeding sites available for $A n$.gambiae. Because its banks have much trailing vegetation, this river provides good breeding sites perennially for An.nili.

We performed night catches of mosquitoes on human bait in four houses per village once a month from April 1989 to March 1990. Specimens were identified immediately and $A n$.gambiae and $A$ n.nili were dissected. Ovaries were observed for parity according to Detinova (1963), and the salivary glands were examined microscopically for the presence of sporozoites.

\section{Results}

The mosquitoes collected were $94 \%$ Anopheles with $6 \%$ of various other genera (Table 1). 


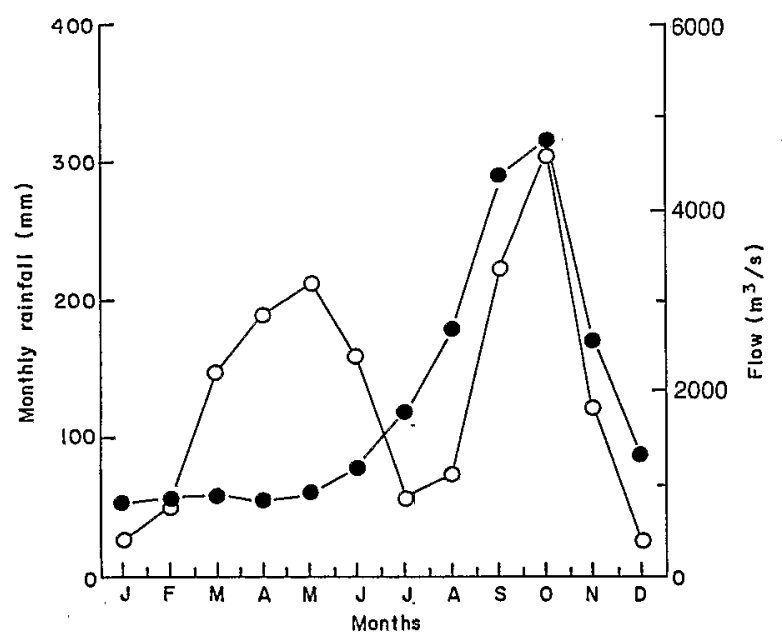

Fig. 1. Monthly rainfall (0) and flow level of Sanaga river (•).

Table 1. Mosquitoes caught on human bait inside houses: combined totals for 12 months $\times 2$ man-night/month $\times 4$ houses $\times 3$ villages.

\begin{tabular}{lrr}
\hline Species & No. & $\%$ of total \\
\hline Anopheles gambiae & 600 & $13.8 \%$ \\
Anopheles nili & 3339 & $76.6 \%$ \\
Anopheles funestus & 131 & $3.0 \%$ \\
Anopheles paludis & 2 & \\
Total Anophelinae & 4072 & $93.4 \%$ \\
& & \\
Culex decens group & 5 & \\
Culex tigripes & 1 & \\
Culex quinquefasciatus & 2 & \\
Aedes vittatus & 8 & $6.1 \%$ \\
Aedomyia furfurea & 2 & $6.6 \%$ \\
Mansonia spp. & 268 & \\
Total Culicinae & 286 & \\
Total Culicidae & 4358 & \\
\hline
\end{tabular}

Seasonal variations in biting rate

An.funestus represented only 3\%, 131/4072 (Table 1) of anophelines collected and is discounted from further discussion.

An.nili was always present (Fig. 2) with an average number of bites per man-night of $23.9 \pm 9.1$, a maximum of 42 in September and a minimum of 11 in November (Table 2). Thus the annual biting rate of An.nili was about 8754 bites/man.

An.gambiae, sensu stricto, was always present (Table 2) with an average of $4.2 \pm 2.8 \mathrm{bites} / \mathrm{man} / \mathrm{night}$. This species showed high densities from December to June (mean $6.5 \pm 0.9 \mathrm{bites} / \mathrm{man} / \mathrm{night}$ ) when the Sanaga river level was low and rock pools were productive breeding-sites, and low densities from July to November (mean $1.1 \pm 0.7$ $\mathrm{bites} / \mathrm{man} / \mathrm{night}$ ) which corresponded to the second rainy

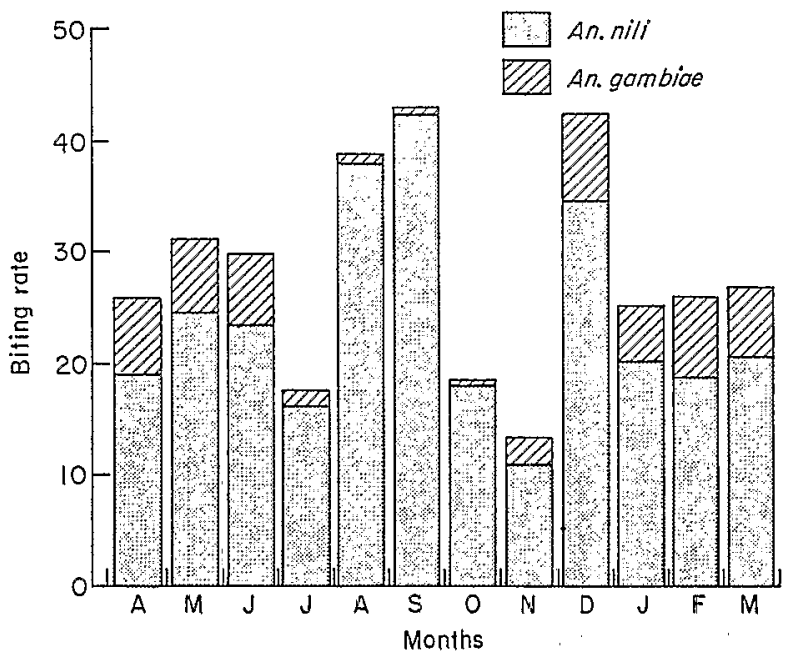

Fig. 2. Monthly mean daily biting rates of An.nili and An.gambiae indoors in Sanaga river villages.

Table 2. Daily mosquito biting rate and monthly malaria inoculation rate due to Anopheles nili and Anopheles gambiae in villages near the Sanaga river.

\begin{tabular}{llllll}
\hline & \multicolumn{2}{l}{ Anopheles nili } & & \multicolumn{2}{c}{ Anopheles } \\
\cline { 6 - 6 } \cline { 5 - 6 } \cline { 5 - 6 } & Biting & Inoculation & & Biting & Inoculation \\
\hline April 1989 & 19.2 & 7.7 & & 6.7 & 13.3 \\
May & 24.6 & 4.5 & & 6.5 & 0 \\
June & 23.5 & 7.9 & & 6.2 & 2.7 \\
July & 16.2 & 2.7 & & 1.2 & 2.6 \\
August & 38.0 & 7.9 & & 0.7 & 0 \\
September & 42.4 & 8.4 & & 0.7 & 0 \\
October & 17.9 & 2.6 & & 0.5 & 0 \\
November & 11.0 & 7.7 & & 2.4 & 5 \\
December & 34.5 & 6.1 & & 7.8 & 11.7 \\
January 1990 & 20.2 & 10.8 & & 4.8 & 8.0 \\
February & 18.6 & 17.1 & & 7.2 & 15.2 \\
March & 20.6 & 21.3 & & 6.2 & 18.9 \\
Mean & $23.9 \pm 9.1$ & $8.7 \pm 5.3$ & & $4.2 \pm 2.8$ & $6.4 \pm 6.5$ \\
Total & 8754 & 104.7 & & 1549 & 77.4 \\
\hline
\end{tabular}

season and the higher levels of the Sanaga river. The annual biting rate of An.gambiae in this area was estimated to be about 1549. Thus inhabitants of these villages were bitten by malaria vectors throughout the year and could receive, in total, about 10,303 bites/person/year from An.gambiae plus An.nili.

\section{Seasonal variations of longevity}

The average parity rate of An.nili was about $64 \%$ ( $n=3106)$, i.e. a daily survival rate of $p=0.87$ according to the formula of Carnevale \& Molinier (1980). The parity rate was at its highest $(70-80 \%)$ when the mosquito 
population density was lowest (20 bites/man/night) and parity was lowest $(40-50 \%)$ when mosquito density was at its peak (40 bites/man/night) (Fig. 3).

For An.gambiae the average parity rate was $65.3 \%$ $(n=547)$, i.e. a daily survival rate of $p=0.85$ calculated as above, not significantly different during the seasons of high $(65.3 \%, n=487)$ and low $(65.0 \%, n=60)$ mosquito population density.

The mean parity rates were similar for An.nili and An.gambiae, although the densities were very different with a ratio of $1: 5$ in favour of An.nili. From the average densities and parity rates the vectorial capacities, estimated with Garrett-Jones' (1964) formula, were 9.7 for An.nili and 1.5 for An.gambiae populations.

\section{Inoculation rate}

Of the 2977 dissected An.nili, 37 (1.24\%) were found positive for malaria sporozoites and this species was found infective at all seasons. The monthly average inoculation rate due to An.nili was $8.7 \pm 5.2$ infective bites/man (Table 2), surpassing 20 infective bites/man/month in March 1990 and falling to about 3 infective bites/man/month in July and October 1989.

Thus An.nili is responsible for perennial transmission of malaria in these villages (Fig. 4) and the total inoculation rate due to this species reached 105 infective bites/man/ year (Table 2).

For An.gambiae the average sporozoite rate was $5.1 \%$ $(n=571)$. The inoculation rate due to this species reached 19 infective bites/man/month at the beginning of the year (Table 2), i.e. a value similar to that of Annili. However the rate varied greatly with population density of An.gambiae and was at its highest from December to April when people received a total of about of 67 infective

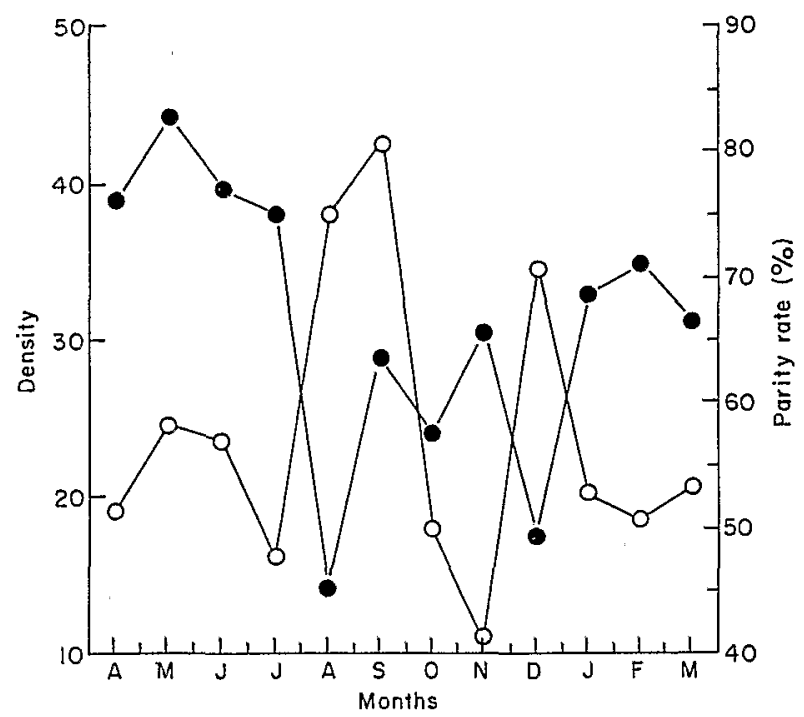

Fig. 3. An.nili monthly density (mean daily indoor biting rate on human bait) (O) and parity rate ( $\bullet$ ) in Sanaga river villages.

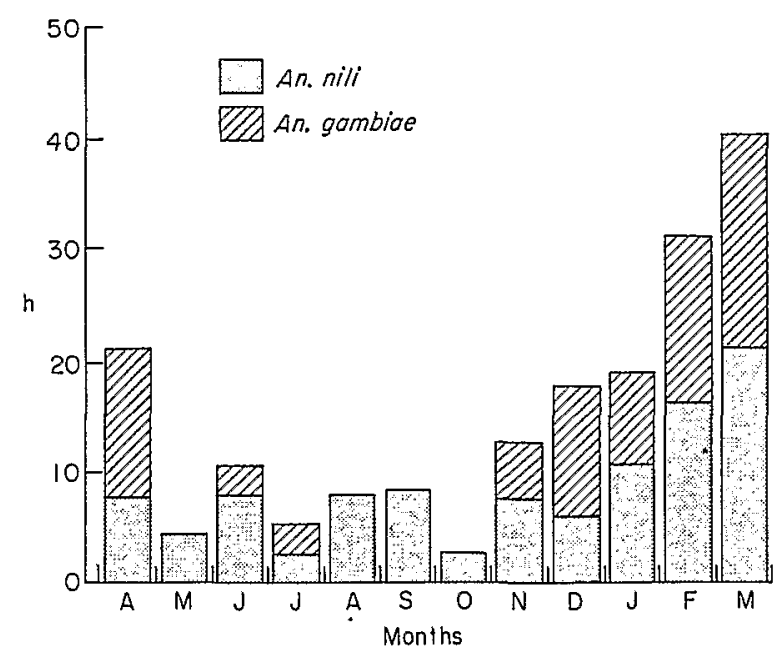

Fig. 4. Monthly malaria inoculation rate due to An.nili and An.gambiae in Sanaga river villages.

bites, i.e. $87 \%$ of all the infective bites due to this vector species in a year (Table 2). For the 6 months from May to October, during the second rainy season, the transmission due to An.gambiae was very weak and in 4 months not one of the 89 specimens examined was found positive (Fig. 4). The total inoculation rate due to An.gambiae was estimated at 77 infective bites/man/year, i.e. only $73 \%$ of that due to An.nili.

Adding the malaria inoculation rates due to both vector species, one can estimate that people of this region receive, on average, about 182 infective bites per person per year.

\section{Discussion}

This study confirms the importance of An.nili as the principal malaria vector in riverside villages of southern Cameroon.

Also in the forest zone of Congo, near a permanent river, it was found that the average parity rate of the An.nili population was about $66 \%(n=4285)$ (Carnevale, 1974) and this species was the main vector during the dry season when An.gambiae was absent. These two species of vectors thus acted in a complementary way, although the bulk of malaria transmission was due to An.gambiae in Congo villages.

In villages of the forest zone in southern Cameroon, near the Sanaga river, the parity rate of $A n$.nili was similar to that observed in Congo and An. nili was the main vector in terms of perennial intensity of human malaria transmission. The seasonal increase of transmission due to An.gambiae is linked to the level of the Sanaga river which recedes to leave rock pools available for An.gambiae breeding. In this area Mouchet (1962) found a density of 5-6 An.gambiae females per house. Thirty years later we found a similar biting rate with an average of $4 \pm 3$ An.gambiae bites/man/night. Adam (1956) found sporozoite rates of $3.1 \%(n=1047)$ and $2.6 \%(n=470)$ for 
An.gambiae and An.nili respectively. Hamon et al. (1956) noticed that the An.nili density by house can reach 20 in the forested area near Yaounde, while we found an average of 24 bites/man/night in 1989. These comparisons show the stability of anopheline populations in villages where no vector control operations have been carried out.

People of these villages receive more than 10,000 bites of Anopheles annually, of which almost 200 are infective, due to An.nili acting as the principal and perennial vector, plus An.gambiae with seasonal peaks. Such a high level of biting and inoculation justifies a vector control programme.

These studies underline the need for entomological evaluation of every malariological situation in relation to the concept of stratification in malariology (W.H.O., 1986).

\section{References}

Adam, J.-P. (1956) Note faunistique et biologique sur les anophèles de la région de Yaoundé et la transmission du paludisme en zone forestière du sud Cameroun. Bulletin de la Société de Pathologie Exotique, 49, 210-220.

Carnevale, P. (1974) Variations saisonnières d'une population d'Anopheles nili (Theobald) 1904 en République populaire du Congo, Cahiers ORSTOM, Série Entomologie Médicale et Parasitologie, 12, 165-174.

Carnevale, P., Bosseno, M.-F. \& Zoulani, A. (1978) Etude du cycle gonotrophique d'Anopheles nili (Theo.) 1904. Cahiers ORSTOM, Série Entomologie Médicale et Parasitologie, $16,43-52$.

Carnevale, P. \& Molinier, M. (1980) Le cycle gonotrophique et le rythme des piqûres d'Anopheles gambiae (Giles), 1902 et d'Anopheles nili (Theobald), 1904. Parassitologia, 22, 173-185.

Curtis, C.F. (1989) Appropriate Technology in Vector Control. CRC Press, Inc.

Detinova, T.S. (1963) Méthodes à appliquer pour classer par groupes d'âge les diptères présentant unc importance médicale. World Health Organization, Monograph series No. 47.

Garrett-Jones, C. (1964) Prognosis for interruption of malaria transmission through assessment of the mosquito's vectorial capacity. Nature, 204, 1173-1175.

Gayral, P., Pichon, G. \& Hamon, J. (1975) Etudes écolögiques sur la faune culicidienne d'vne selique forestière en zone de savane africaine. Annales de la Société Entomologique de France, $11,551-586$.

Gillies, M.T. \& De Meillon, B. (1968) The Anophelinae of Africa South of the Sahara (Ethiopian Zoogeographical Region). Publications of the South African Institute for Medical Research, No. 54 .

Gillies, M.T. \& Coetze, M. (1987) A supplement to the Anophelinae of Africa South of Sahara. Publications of the South African Institute for Medical Research, No. 55.

Hamon, J., Adam, J.-P. \& Grjebine, A. (1956) Observations sur la répartition et le comportemement des anophèles de l'Afrique équatoriale française, du Cameroun et de l'Afrique occidentale. Bulletin of the World Health Organization, 15, 549-591.

Hamon, J. \& Mouchet, J. (1961) Les vecteurs secondaires du paludisme humain en Afrique. Médecine Tropicale, 21, 643-660.

Krafsur, E.S. (1970) Anopheles nili as a vector of malaria in a lowland region of Ethiopia. Parassitologia, 12, 47-61.

Le Goff, G., Verhave, J.-P., Robert, V. \& Carnevale, P. (1990) Influcnce de la proximité d'un fleuve sur la transmission du Paludisme dans la forêt du Cameroun. VII International Congress of Parasitology, Paris, August 20-24. Bulletin de la Société Française de Parasitologie, 8, supplément 2, p. 1180.

Mouchet, J. (1962) Influence des fleuves sur la biologie d'Anopheles gambiae pendant la saison sc̀che dans le Sud-Camcroun. Bulletin de la Société de Pathologie Exotique, 55, 1163-1171.

Service, M.W. (1964) The behaviour of Anopheles nili Theo in sprayed huts in Northern Nigeria. Journal of Tropical Medicine and Hygiene, 67, 11-12.

W.H.O. (1986) Expert Committe on Malaria. Eighteenth Report. Technical report Series, 735.

Accepted 22 November 1991 